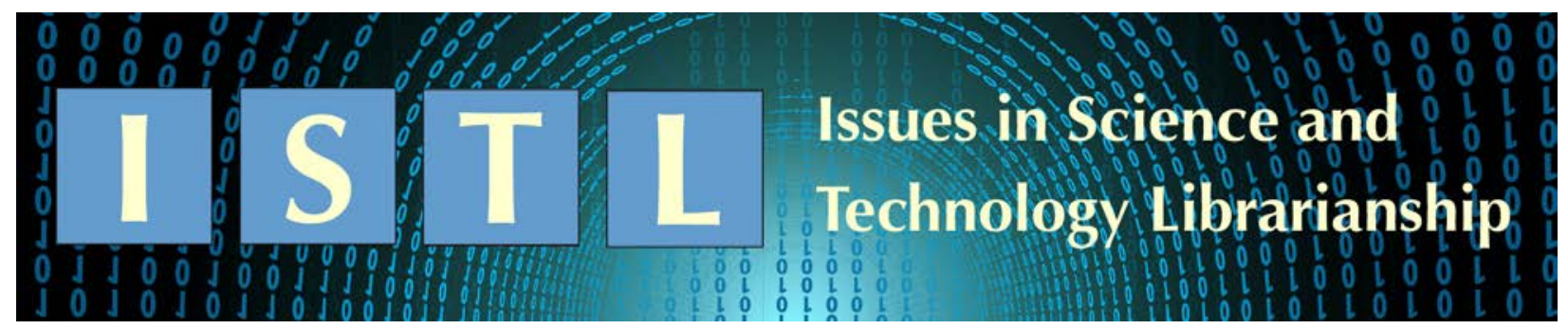

\title{
A Study of the Copyright Renewal Rate for Maps
}

\author{
Linda Musser \\ Fletcher L. Byrom Earth and Mineral Sciences Library \\ Penn State University \\ 105 Deike Building \\ University Park PA 16802 USA \\ lindamusser@psu.edu
}

\begin{abstract}
This study examines the copyright renewal of maps published in the United States from 1923 to 1950 and compares the results with a recent study of copyright renewals for books. Results indicate that, while the average copyright renewal rate for maps appears similar to that of books, the average was skewed higher by a single publisher whose renewal rate was much higher than average. With the data from that publisher excluded, the average copyright renewal rate dropped to $10 \%$, meaning that a significant number of maps copyrighted in the United States in the first half of the 20th century are probably in the public domain due to lack of copyright renewal. This has implications for library map digitization projects, as much more content may be available for scanning and archiving than was previously thought.
\end{abstract}

\section{Introduction}

With the advent of large-scale digitization projects that are available to the public for searching, interest in access to digitized works has increased. Examples of these projects include the Internet Archive, Google Books, and the HathiTrust Digital Library, among others. The oftquoted rule of thumb - that works published during or after 1923 are still in copyright - leads librarians and others to consider all such works off-limits for access. (Note: As of January 1, 2019 that date has increased to 1924 and will increase annually by one year, since current United States (U.S.) copyright law allows materials to remain in copyright for 95 years.) Efforts to review the copyright status of some of these works have proven valuable, however, as research by Wilkin (2017) indicates that over 50\% of materials published in the United States between 1923 and 1963 are now in the public domain, meaning that hundreds of thousands of works published during those years can be made freely available.

While this is good news, most large-scale digitization projects have focused on books and journals, bypassing other formats such as maps. Many libraries have digitized maps but largescale projects are fewer in number, and the focus of libraries has been on works already out of copyright, i.e., pre-1923 works or works already in the public domain, such as those published by the U.S. government. Examples of large collections that focus on works out of copyright include 
the David Rumsey Map Collection, Old Maps Online and the Library of Congress. Fire insurance maps, particularly those by the Sanborn Map Company, have been the focus of much attention for digitization. In 2002, the University of Utah documented their efforts to digitize Sanborn maps (Arlitsch 2002), and today scans of fire insurance maps published before 1923 are freely available for locations across the United States.

This study attempted to determine whether the copyright renewal rate for maps mirrored that found by Wilkin for books. If the pattern for maps is similar, then tens of thousands of maps are eligible to be digitized and made freely available. This is particularly important, as we are in an era where libraries are downsizing print collections to make space for other services. Maps pose storage challenges and are often the target of downsizing and withdrawal. Where a print book can be discarded with the knowledge that a digital facsimile exists, the same frequently cannot be said for maps. Large-scale digitization of copyrighted maps published after 1922 are uncommon and have been undertaken by just a handful of publishers, such as National Geographic and the Sanborn Map Company (by ProQuest).

Extensive collections of digitized works have prompted increased interest in checking on the copyright status of works. The mechanics and rules governing copyright renewal research have not changed in decades, although the tools required to perform a review have become more accessible in recent years. With the scanning and full text OCRing of the Catalog of Copyright Entries (U.S. Copyright Office 1906-), creation of new tools such as Stanford University's Copyright Renewal Database (Stanford University 2019), and initiatives on the part of the U.S. Copyright Office to move copyright data online, the process of checking for copyright renewal has become much easier.

The HathiTrust Digital Library is a collaborative repository for digitized content from multiple library collections. It holds over 16 million full-text indexed (via OCR) and digitized volumes comprising over eight million titles. In 2008, the HathiTrust's Copyright Review Management System (CRMS) team developed a standardized process for copyright review and began reviewing volumes in the HathiTrust corpus (HathiTrust 2018). Since 2008, over 600,000 volumes in the HathiTrust collection published from 1922 to 1963 have been reviewed, with over 50\% found to be in the public domain (HathiTrust 2018). The data gleaned from this project has been fodder for several studies, including a study by Wilkin (2017) on renewal rates for books that inspired the current study. A 2014 study examined copyright renewals of Sanborn fire insurance maps in the Penn State University Libraries collection, finding that $52 \%$ were in the public domain and 48\% had copyright renewed (Musser 2014). This partially paralleled the results of Wilkin, who reported that $53 \%$ of works examined were in the public domain.

Wilkin's study utilized data from the CRMS to calculate a copyright renewal rate of $16 \%$ for monographs published from 1923 to 1963, which is much less than that reported in the study by Musser. The current study was undertaken to more closely examine the copyright renewal rate for maps to determine how the renewal rate compared to that of monographs. For maps published from 1951 to 1963, the U.S. Copyright Office did not report renewal data by format. Therefore, the period studied was from 1923 to 1950, thirteen years shorter than in the Wilkin study. 


\section{Methods}

Since maps are not typically included in the HathiTrust corpus, except as parts of books, an alternate method for evaluating copyright renewal was required. Volumes of the Catalog of Copyright Entries were examined to identify copyright ownership information. From the annual reports of the U.S. Copyright Office (2019), data were collected on the number of copyright renewals for maps recorded per year, as well as the number of maps copyrighted 27 years earlier, i.e., the original copyright date. Prior to 1992, works were required to have their copyright renewed 27 years after the original copyright date. If the copyright was not renewed within the requisite time period, then the work became part of the public domain. Rules for copyright renewal changed in 1992, when the U.S. Congress made renewals for works published after 1963 automatic. Therefore, the focus of this study was restricted to pre-1964 works. Works published in the United States prior to 1923 are already in the public domain. As stated earlier, renewal data for maps published from 1951-1963 were not separately reported by the U.S. Copyright Office, so this study was restricted to maps published from 1923 to 1950, those requiring renewal from 1950 to 1977.

Some works published during this period did not require renewal to remain in copyright due to international treaty, such as certain works published abroad (see Hirtle 2008 for details). Relatively few of the maps copyrighted during the years of this study appear to meet these criteria, and this study did not attempt to identify or enumerate these works.

\section{Results}

An average copyright renewal rate was calculated for the overall time span (1923-1950), as well as for each year. As reflected in Table 1, the renewal rate ranged from a high of $37 \%$ to a low of $2 \%$, for an average result of $18 \%$ over the 28 -year period, which is similar to the $16 \%$ for monographs reported by Wilkin. There is a significant increase in renewals in 1977, which is largely attributable to a single publisher's renewal activity. An abrupt decline in renewals was noted beginning in 1960, mirroring that reported in Wilkin's study of books. Differences between this study and that of Wilkin are two-fold. Wilkin used a 40-year span of data for his analysis, compared to the 28 years available for this study. The CRMS process, upon which Wilkin based his analysis, involved not only checking the renewal data in the Catalog of Copyright Entries, but also examining the works themselves for appropriate copyright marks, which were required by law. In the Wilkin study, an additional 1\% of items fell into the public domain due to a lack of the required mark. The current study did not undertake to examine the physical maps themselves. Otherwise, the average renewal rate for maps might be slightly lower, based upon this criterion.

In the Wilkin study of monographs, three categories of copyright status were identified: public domain (53\%), in copyright (16\%), and indeterminate (30\%). Works categorized as indeterminate were those whose copyright renewal status was unclear at the time of the review. For example, works with photographs could be classified as indeterminate, as the photographs may have separate copyright protection from the rest of the work. The current study did not attempt to determine rates of indeterminate copyright status, nor does this study attempt to identify those works, described previously, that did not require formal renewal to remain in copyright (foreign works, etc.). 
Table 1. Maps copyrighted, 1923-1950 and map copyright renewals 1950-1977.

\begin{tabular}{|c|c|c|c|c|c|c|c|}
\hline $\begin{array}{c}\text { Year of } \\
\text { original } \\
\text { copyright }\end{array}$ & $\begin{array}{c}\text { Renewal } \\
\text { year }\end{array}$ & $\begin{array}{l}\text { Number of } \\
\text { maps } \\
\text { copyrighted }\end{array}$ & $\begin{array}{l}\text { Number of } \\
\text { Sanborn } \\
\text { maps } \\
\text { published }\end{array}$ & $\begin{array}{l}\text { Total map } \\
\text { renewals* }\end{array}$ & $\begin{array}{l}\text { Number of } \\
\text { Sanborn } \\
\text { maps } \\
\text { renewed }\end{array}$ & $\begin{array}{l}\text { Percent of } \\
\text { Sanborn } \\
\text { maps } \\
\text { renewed }\end{array}$ & $\begin{array}{c}\text { Percent of } \\
\text { all maps } \\
\text { renewed }\end{array}$ \\
\hline 1950 & 1977 & 1,638 & 1,026 & 603 & 0 & $0 \%$ & $37 \%$ \\
\hline 1949 & 1976 & 4,627 & 590 & 527 & 0 & $0 \%$ & $11 \%$ \\
\hline 1948 & 1975 & 2,855 & 506 & 517 & 0 & $0 \%$ & $18 \%$ \\
\hline 1947 & 1974 & 3,526 & 300 & 201 & 0 & $0 \%$ & $6 \%$ \\
\hline 1946 & 1973 & 2,558 & 256 & 129 & 0 & $0 \%$ & $5 \%$ \\
\hline 1945 & 1972 & 1,709 & 349 & 120 & 0 & $0 \%$ & $7 \%$ \\
\hline 1944 & 1971 & 494 & 369 & 56 & 0 & $0 \%$ & $11 \%$ \\
\hline 1943 & 1970 & 737 & 473 & 45 & 0 & $0 \%$ & $6 \%$ \\
\hline 1942 & 1969 & 1,217 & 416 & 99 & 0 & $0 \%$ & $8 \%$ \\
\hline 1941 & 1968 & 1,398 & 456 & 79 & 0 & $0 \%$ & $6 \%$ \\
\hline 1940 & 1967 & 1,622 & 390 & 116 & 0 & $0 \%$ & $7 \%$ \\
\hline 1939 & 1966 & 1,566 & 402 & 92 & 0 & $0 \%$ & $6 \%$ \\
\hline 1938 & 1965 & 1,200 & 429 & 112 & 0 & $0 \%$ & $9 \%$ \\
\hline 1937 & 1964 & 1,198 & 313 & 110 & 0 & $0 \%$ & $9 \%$ \\
\hline 1936 & 1963 & 1,444 & 304 & 119 & 0 & $0 \%$ & $8 \%$ \\
\hline 1935 & 1962 & 1,343 & 269 & 96 & 13 & $5 \%$ & $7 \%$ \\
\hline 1934 & 1961 & 1,250 & 275 & 21 & 17 & $6 \%$ & $2 \%$ \\
\hline 1933 & 1960 & 1,178 & 474 & 49 & 37 & $8 \%$ & $4 \%$ \\
\hline 1932 & 1959 & 1,774 & 547 & 487 & 443 & $81 \%$ & $27 \%$ \\
\hline 1931 & 1958 & 2,940 & 1,047 & 1,046 & 1,027 & $98 \%$ & $36 \%$ \\
\hline 1930 & 1957 & 2,554 & 1,320 & 912 & 810 & $61 \%$ & $36 \%$ \\
\hline 1929 & 1956 & 2,232 & 1,536 & 779 & 718 & $47 \%$ & $35 \%$ \\
\hline 1928 & 1955 & 2,862 & 1,223 & 853 & 767 & $63 \%$ & $30 \%$ \\
\hline 1927 & 1954 & 2,677 & 1,433 & 826 & 729 & $51 \%$ & $31 \%$ \\
\hline 1926 & 1953 & 2,647 & 1,105 & 743 & 620 & $56 \%$ & $28 \%$ \\
\hline 1925 & 1952 & 2,222 & 1,158 & 474 & 361 & $31 \%$ & $21 \%$ \\
\hline 1924 & 1951 & 2,265 & 1,182 & 572 & 609 & $52 \%$ & $25 \%$ \\
\hline 1923 & 1950 & 2,042 & 1,076 & 315 & 293 & $27 \%$ & $15 \%$ \\
\hline Totals & 28 years & 55,775 & 19,224 & 10,098 & 6,444 & $34 \%$ & $18 \%$ \\
\hline
\end{tabular}


Musser's study reported a 48\% copyright renewal rate for Sanborn maps, which is much higher than this study's calculated rate of $18 \%$ average renewal rate for maps. To explore this difference further, individual map copyright renewals were analyzed by name of copyright holder, usually the publisher of the map. Findings indicate that map copyright renewals were dominated by a small number of publishers - the Sanborn Map Company (64\%) and Tobin Aerial Surveys (19\%), followed by Midcontinent Map Company (3\%), Rand McNally and Company (3\%), and the Hammond Map Company (3\%). First among these was the Sanborn Map Company, publisher of fire insurance maps. Fire insurance maps documented street layouts and the size, shape, construction materials, etc. of buildings for thousands of towns and cities in the late 19th and early to mid-20th century. They are an extremely valuable resource for the study of urban growth and are heavily used by historians and genealogists. The Sanborn Map Company produced more than a million map sheets describing approximately 12,000 American cities and towns (Sanborn Map Company 2019). For the period 1950-1977, the Sanborn Map Company submitted 6,444 renewals, or 34\% of their maps eligible for renewal. This figure is deceptive, however, as few Sanborn maps had their copyrights renewed after 1960 (none after 1962), so the average renewal rate dropped significantly towards the end of the time period studied (see Table 1). The variation in renewal rate was extreme, ranging from $98 \%$ to zero.

\section{MAPS COPYRIGHTED FROM 1923-1932}

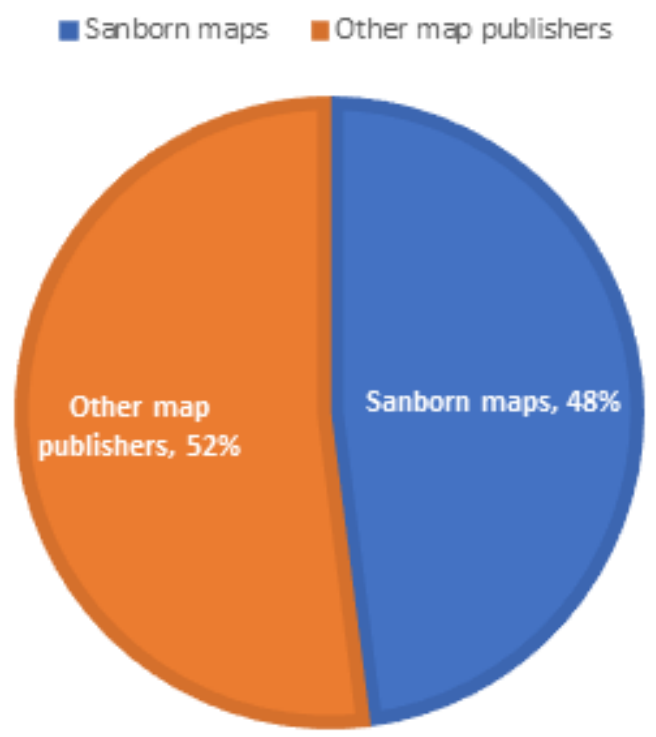

Figure 1. Publisher distribution of maps copyrighted from 1923-1932

When determining the average copyright renewal rate for maps, the dominating impact of a prolific publisher such as the Sanborn Map Company must be taken into account. From 19231932, the Sanborn Map Company registered copyrights for nearly half (48\%) of all copyrighted maps (see Figure 1). Twenty-seven years later, from 1950-59, that company's renewals amounted to nearly all (91\%) of the maps renewed (see Figure 2). These results indicate that the calculated average renewal rate of $18 \%$ based on data from Table 1 is probably inaccurate for many maps due to the outsized impact of the Sanborn Map Company. Sanborn fire insurance maps have higher copyright renewal rates than average and thus have an outsized impact on the overall average map copyright renewal rate. To determine a renewal rate for other copyrighted 


\section{MAPS COPYRIGHT RENEWALS FROM 1950-1959}

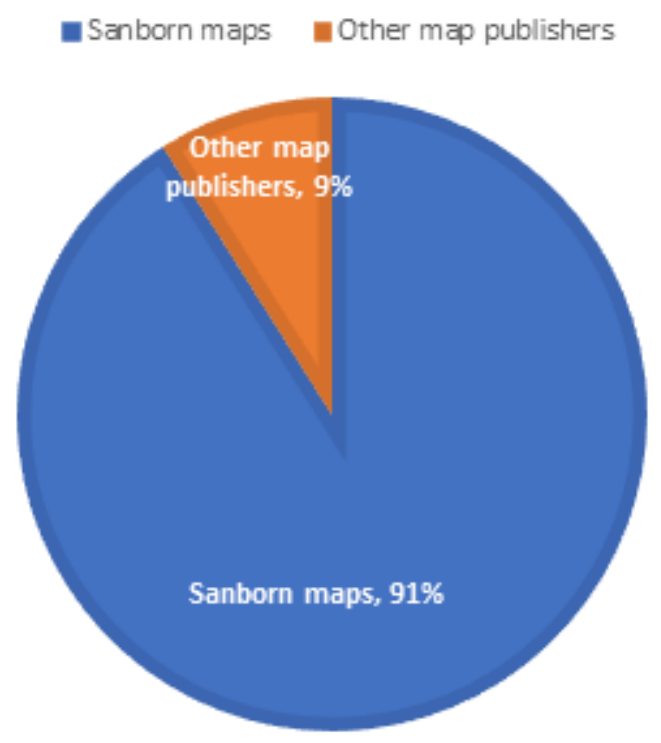

Figure 2. Publisher distribution of maps renewed from 1950-1959

maps, the numbers for Sanborn maps were removed from the totals (of both renewals and originally published), and separate renewal rates were calculated. Annual numbers of Sanborn maps published were extracted from data at the Library of Congress, and annual numbers of Sanborn map renewals were compiled from the Catalog of Copyright Entries. For the period 1950-1977, Sanborn maps had an average copyright renewal rate of 34\%, and other maps had an average copyright renewal rate of $10 \%$, thus confirming the strong impact of the Sanborn Map Company on average map copyright renewal rates.

\section{Discussion}

The average copyright renewal rate for maps appears similar to that for monographs but is highly dependent on the publisher, with Sanborn maps having a much higher average renewal rate than publishers of other maps. The reasons for the significantly lower copyright renewal rate for nonSanborn maps are worth considering. The nature of the content of maps themselves are such that there is limited re-sale value 27 years after the initial publication. Consider that the most common type of commercial map, the road map, was generated to illustrate geography at the time of publication. Twenty-seven years hence, an old road map has little value for current travelers, though it retains intellectual value as an historical resource. Other considerations might be the relatively low profit involved in most map publications and changing user needs and technology. Ultimately, when Sanborn maps are excluded from the corpus of all copyrighted maps, the average copyright renewal rate for maps is significantly lower than that of books. Many maps copyrighted prior to 1964 are now in the public domain.

The abrupt decline in copyright renewals in the early 1960s that was originally reported by Wilkin for books was visible in this study as well. However, the reason for the drop remains unknown. The rate of map publication dropped by about a third from 1932 to 1933, whereas renewals from 1959 to 1960 dropped by 85\%. Examination of the annual reports of the U.S. Copyright Office from 1959 and 1960 yielded no obvious reasons for the drop in renewals. The 
U.S. Copyright Office states that overall renewal rates were stable over this period (U.S. Copyright Office. Annual Report 1960, p.13), so it may be possible that the drop is the result of changes in the map publishing industry, particularly the Sanborn Map Company. By the late 1950s, the company had greatly reduced production of fire insurance maps, the last of which they published in 1961 (Ristow 1968, p.213).

\section{Conclusion}

Many digital repositories, like the HathiTrust Digital Library and Google Books, have focused on formats other than maps. The groups that have completed large-scale digitization of maps, such as David Rumsey, the Library of Congress and others, have focused on maps that are, on the surface, no longer in copyright, i.e., published prior to 1923. Given that the copyright renewal rate for maps, with the exception of Sanborn fire insurance maps, is very low (10 \%) for works published in the United States prior to 1964, librarians should consider increasing the corpus of scanned historic maps from this time period, particularly as space pressures are forcing many map libraries to reduce print collections.

\section{Acknowledgements}

Feedback from Brandy Karl, Amy Paster, and Nan Butkovich, along with the comments from the reviewers and editor were very helpful in improving this article. I thank you.

\section{References}

Arlitsch, K. 2002. Digitizing Sanborn Fire Insurance Maps ${ }^{\mathrm{TM}}$ for a full color, publicly accessible collection. D-Lib Magazine 8(7/8). [cited 2019 Dec 6]. Available from:

http://www.dlib.org/dlib/july02/arlitsch/07arlitsch.html.

HathiTrust. 2019. Copyright Review Program. Ann Arbor, MI: HathiTrust. [cited 2019 Dec 6]. Available from: https://www.hathitrust.org/copyright-review.

Hirtle, P. 2008. Copyright renewal, copyright restoration, and the difficulty of determining copyright status. D-Lib Magazine 14 (7/8). [cited 2019 Dec 6]. Available from: http://www.dlib.org/dlib/july08/hirtle/07hirtle.html.

Musser, L. 2014. Copyright status for Sanborn maps. base line 35(4): 25-26. [cited 2019 Dec 6]. Available from: http://www.ala.org/rt/files/publicationsab/baseline/35-4.pdf\#page=25.

Ristow, W. W. 1968. United States fire insurance and underwriters maps, 1852-1968. Quarterly Journal of the Library of Congress 25(3): 194-218. [cited 2019 Dec 6]. Available from: https:// hdl.handle.net/2027/umn.31951d029745846.

Sanborn Map Company. 2019. Sanborn Fire Insurance Maps. Colorado Springs, CO: Sanborn Map Company. [cited 2019 Dec 6]. Available from: https://www.sanborn.com/sanborn-fireinsurance-maps.

Stanford University. 2019. Copyright Renewal Database. Stanford, CA: Stanford University. [cited 2019 Dec 6]. Available from: https://exhibits.stanford.edu/copyrightrenewals. 
U.S. Copyright Office. 1906-. Catalog of Copyright Entries. Washington, DC: Library of Congress. [cited 2019 Dec 6]. Available from: https://onlinebooks.library.upenn.edu/cce.

U.S. Copyright Office. 2019. Annual Reports. Washington, DC: U.S. Copyright Office. [cited 2019 Dec 6]. Available from: https://www.copyright.gov/history/annual_reports.html.

Wilkin, J. P. 2017. How large is the ‘public domain’? A comparative analysis of Ringer's 1961 copyright renewal study and HathiTrust CRMS data. College \& Research Libraries 78(2): 201-218. DOI: https://www.copyright.gov/history/annual_reports.html. 